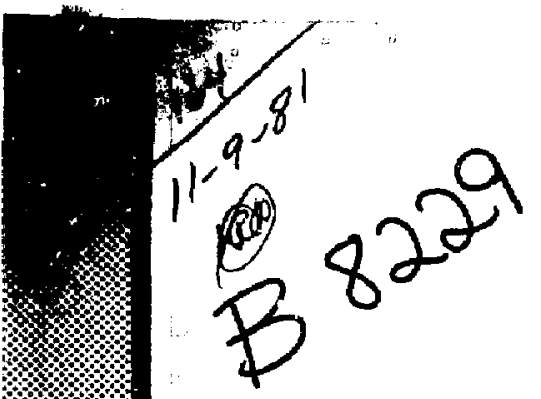

OETOBER 1981

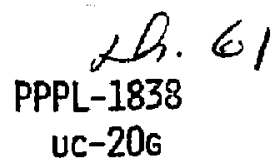

MASTER

\title{
GYROKINETIC APPROACH IN \\ PARTICLE SIMULATION
}

BY

W. W, LEE

\section{PLASMA PHYSICS LABORATORY}

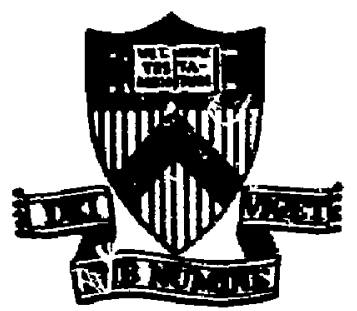

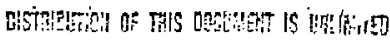

\section{PRINCETON UNIVERSITY PRINEEYON, NEW JERSEY}

This work was supported by the U.S. Dejartment of Energy Contract NO. DE-AC03-76-CHO 3073. Reproducfion, Eranslation, putliration, use and discosal, ir whole or ir part, by or for the United States government is peraitied. 


\title{
"Gyrokinetic Aproach In Particle SImulation" \\ I. W. T,ee \\ Plasma Physics rahoratory, Princeton lintuersity \\ Princeton, N.J. $\quad$ n8544
}

\begin{abstract}
Ahstract
A new scheme for particle simulation lased on the nyrophiso-averaped Vlasov equation has been developer. It Is sultable for studying low-frequency microinstabiltiles and the associated anomalous cransport in maglletically confined plasias. The scheme retains the gyroradius effects hut not the gyromotion; it is, therefore, far more efficlent and versatile than the cisnventional ones. Furthermore, the reduced vlasov equation is also amenabin to analytical studies.
\end{abstract}

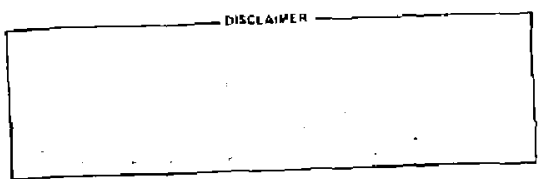




\section{i. Introduction}

ryroklnetlc aplroach has been whely used in recont vears for gtudylng

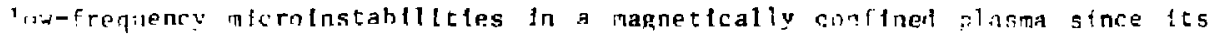

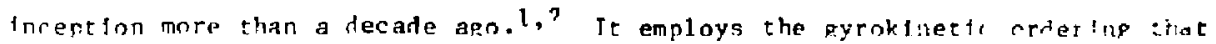
I he characterfate frequencles of the waves and geyroratll are smal comparet $\therefore$ the gurnfrequenctes and unperturned scale lengths, resonetivisy, and

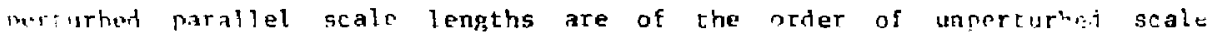

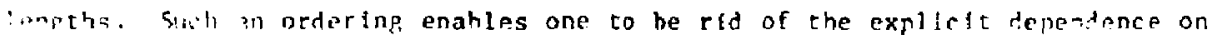
the phise angie of the vlasov equation through gyrophase-averagling whlle rataining the syroradius effects to the arbitrary value of the pyrmitius over the pernenticular scale length. Fintte gyroradius effects, as we krow, are -senclal far many mirrolnstabllitles of interest in magnetic coritament ievicos such as tokamaks. Contrary to the ind 1 ginal approach, ratio has rerently teveloped a gyr.skinetic techninue which first transforms the particle

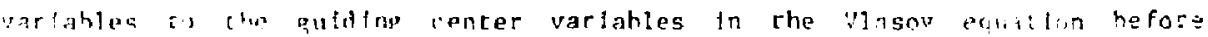

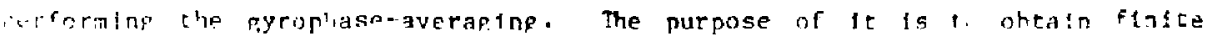

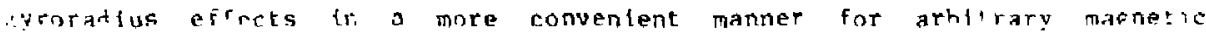

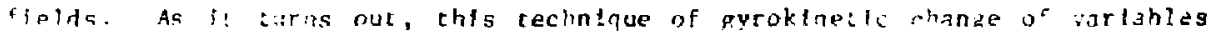

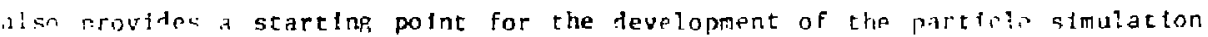
arhung reported here.

Particle cole simulation has long been recognized as a tectui tool for underatandfng nonlinear plasma hehavtor and has contrlbuted slentficantly in thls regard over the years. In the area of nicroinstabllittes in rokanaks, the cxritation of the convective cells due to unstable trift waves ${ }^{4}$ and the magnetic field line reconnection caused hy ghear-Alfuen waves are jugt two examples. However, not unl tke other numerlcal schemes, particle code 
simulation also has its share of limitations. For convent lonal cories which operace on the flrst prtnctples of Newtonian dynamics, the time step for particle pushing is limited by the highest characteriacle frequency in the plasma, which can be several orters of magnitude larger than the frequency of interest. It is, therefore, rather tneffictent, if possitile at all, to stmulate low-frequency phenomena with such a code. Efforts have heen mare in the past to eliminate high frequency osclliations in the simulation plasma. For example, drift-kinetic approxtmation for electrons has been made in the codes used for the Investlgations tn Refs. 4 and $5.6,7,8$ However, the lower hybrit osclilation, whlch represents the highest frequency in the plasma for such cases, is stll1 much ?arger than the frequency of interest. In this naper, we will present a particle simulation scheme which keeps fintte gyroradius effects that are vttal to the physics at hant, hut, at the same tine, eliminates the oscfllations assoclated with partifle gyromotion. Henceforth, particle pushing can he accomplished in the time scale of the lowfrequency mferoinstahilftes. The scheme 1s, therefore, most suttahle for the simulation of rokamak plasmas.

Recently, Iong-tine-step particle stmulation has also heen tackled on a different front. Several impitclt schemes have been developed, in which the high-frequency osclilattons are filtered out through numerical methods.9,10,11 They represent a baslc difference in philosophy than the scheme discussed in this paper as well as those in Refs. 5 and $R$, tn which the elimlnation of high-frequency oscillations is contingent upon the underlying physlcs. Although the inplicte schernes are more general in nature, their applicablify to two and three-dimenstonal tokamak plasmas has yet to he demonstrated.

In the present paper, the focus is on the development of an electrostatic 
particle simulation scheme in the slab geometry. The scheme 1 s accutate linearly for arhitrary values of $k_{1} \rho_{1}$, where $i_{1} 1$ s the fon firorartis. Nonlinearly, it is valid for $k_{1} p_{1}<1$. The two-and-ont-half-itimenglonal

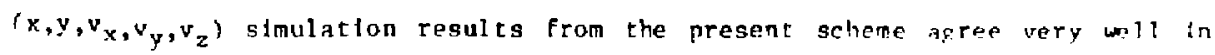
every aspect of the Instabllity with those ohtalned parller liatng rarticla

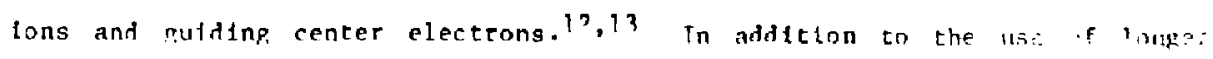
time-steps for particle pushing, the scheme also ran affort to use fewer patticles to stufy weaker instahilities hecalss the numerical nolse asarsiated with the particle gyration is no longer a problem. Therefore, lt cepresents $\dot{c}$ tremendous saving In computing resources. Since the procedures descrihed here ts rather peneral, they can he used easlly to ohtain the electenstatic and electromagnet1r (low- A) versions of the scheme in the toroldal geometry. In view of the recent development of the multiple-scale particte stmulatini

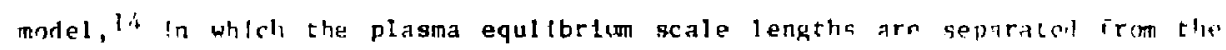
perturhaton scale lengths, it 18 now posstble to simuliri fully threcu-

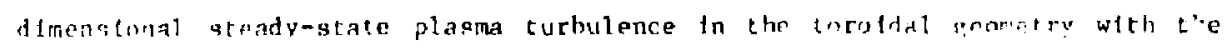
present generitior a computers. This paper representa the fir l ster towart that itrertion.

The paper is organtzed as follows. In sec. Ti, the hasts fomblition ur the eirotinetit: equation in eeneral seometry is prescinted. The procedures for tie development of electrostatc pacticio simulation scheme tn the slab ownetry is discussed in retell in Sec. TIt. The partfclin pushting algorlthth and the gimulation regults are glven in Ser. IV. together with thetr conparlsons wh previous particle core results. Canclustuns and recommendations for future work are given in Sec. V. 


\section{Basfe Formulation}

Let us first apply Catto"s gyrokinetic change of vartables ${ }^{3}$ from $\underset{\sim}{x} \underset{\sim}{v}$ to $\underset{\sim}{R}, \mu, v, \downarrow$ to the Vlasov equation in genetal geometry,

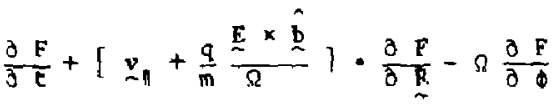

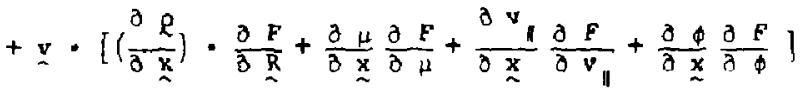

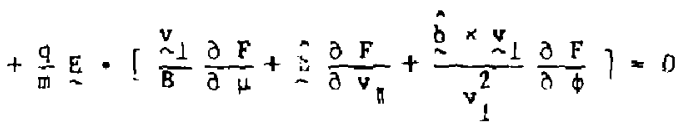

where $F\left(R, \mu, v_{n}, \phi, C\right)$ is the distribution function, $E(x)$ is the perturhed

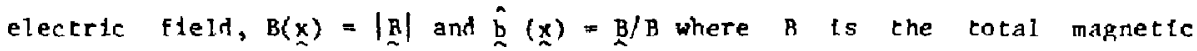
fielt, $\mu=v_{1}^{2} / 2 B, 0=\underline{y}_{1} \times \hat{b} / 0, \Omega=q B / m c-y_{i}=v_{1}\left(\cos \phi \hat{e}_{1}+\sin \phi \hat{e}_{2}\right)$, ${\underset{\sim}{4}}_{4}=v_{\pi} \hat{i}, \hat{b}=\hat{e}_{i}^{-} \times \hat{e}_{2}, \underline{R}=\underline{x}+\beta$, and

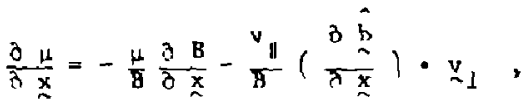

$$
\begin{aligned}
& \frac{\partial \underset{v}{d x}}{\partial \underset{\sim}{x}}=\left(\frac{\partial \underline{b}}{\partial \underline{x}}\right) \cdot \underset{\sim}{v} \text {, } \\
& \frac{\partial \phi}{\partial \underset{x}{x}}=\frac{v_{u}}{v_{1}^{2}}\left(\frac{\partial \hat{b}}{\partial \underset{x}{x}}\right) \cdot\left({\underset{v}{v}}_{1} \times \hat{b}\right)+\left(\frac{\partial \hat{e}_{2}}{\partial \underline{x}}\right) \cdot \hat{e}_{-1} \text {. }
\end{aligned}
$$

For a low-g (= plasma pressure/magnetle pressure) plasma, the electrtc fleld is given by

$$
E=-\frac{\partial}{\partial x}-\frac{1}{c} \frac{\partial A_{n}}{\partial t},
$$


where $\Phi(x)$ is the electroatatic potential and $A_{n}(x)$ is the parallel vectror

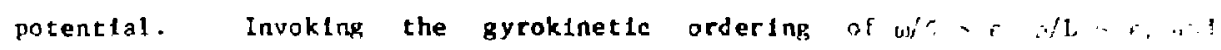
L - I. where $\varepsilon$ ts a smallness parameter, o the gyroradlus, I, the pqullihrlui. scale lefigth and $L_{H}$ the perturber porallel scale length, one can wlit. tnon the lowest order equation of Fq. (1) as

$$
\therefore \frac{x}{5-\frac{F}{5}}=n .
$$

Here the perturhed fields are also constdered to be $O(\varepsilon)$. With

$$
F=E+r g(\phi)
$$

where $f$ is the solution of $\mathrm{Eq} .(3)$ and $1 \mathrm{~s}$ independent of phase $d, \mathrm{Fq}$ ( (1) tO the next order reduces to

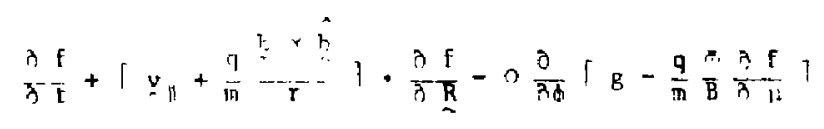

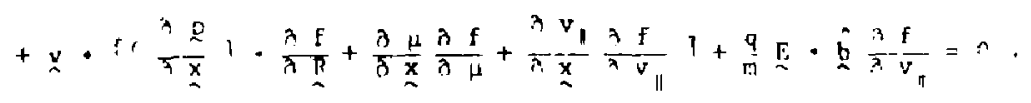

Ninte that the relations of

$$
x+2 x-\frac{x}{R},
$$

which is correct to the order $E$, and

$$
0 \frac{\partial}{\partial}=-y_{1} \cdot \frac{\lambda}{\hbar} \frac{\pi}{2}
$$


have been used In arrtvirg at FA. (5). By assuming that all the field quantities are Independent of and by caktng the gyrophase average of $\mathrm{E}$. (5), wen recover the usual drift-kinetic equation

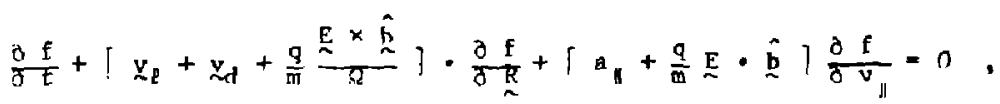

where

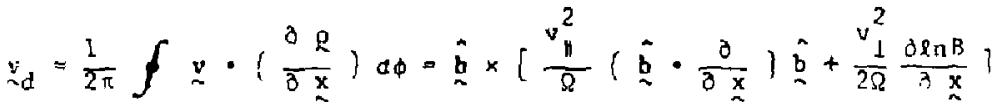

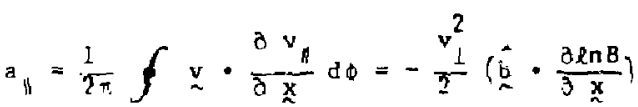

are the curvature and $\nabla b$ drifts and the parallel acceleraifon, respectively. The parallel drift is ignored in $\mathrm{Eq}$. (9) because it is higher order in $\varepsilon,{ }^{3}$ and $\int \underset{v}{v} \cdot\left(\partial_{\mu} / \partial_{\alpha}\right) d \phi=0$. It should he mentloned here that, together with Fa. (2) and

$$
\mu=v_{1}^{2} / 2 B=\text { constant, }
$$

Eq. (A) can be used for particle pushing for electrons for a low-B plasma in the general geometry. If we now assume that $f$ is the part of the distribution function which can be described by the drift-kinetic equation, Eq. (5) then Indicates that $g=(g / m)(\Phi / B)(\partial f / O \mu)$ which givts

$$
F=f+\frac{q}{\pi} \frac{\partial E}{\delta}
$$

Substcuting Bq. (9) 1nto Fq. (1), and using agatn Eqs. (5) and (9) together 
wich

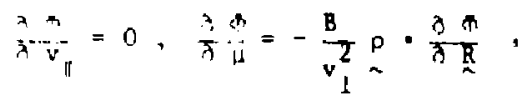

we can wrtte the gyroktnetic equation as

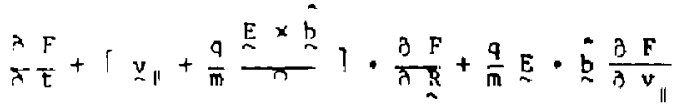

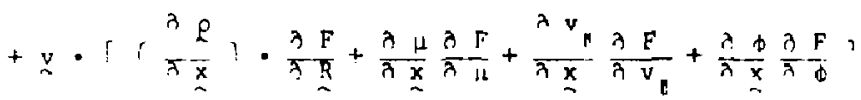

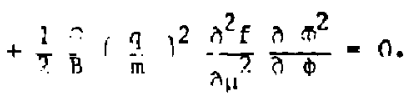

The last term in $\mathrm{Fq}$. (11) can he eliminated through gytophase-averaglig. Thus, this equation, which is the reduced form of Eq. (1), is amenable to the development of gyrokinetic particle simulation schemes for electrostatic as weIl as flnlte-p plasmas. In the following sectlons, our focus wil be min the revelopment of an electrostatc particle simulacton scherine ta the siab peometry. Morc peneral cases using Eq. (l1) will be reported later.

\section{TII. Fiectrogtatle Oyrokinet1s $\mathrm{s}$ ln Slah}

The pyrophase-averaged electrogtatic gyrokinetic equation In the slah peometry can he ohtafner from Eq. (11) hy neglecting the geometric rerma, and it takes the form

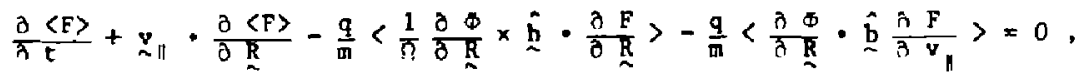




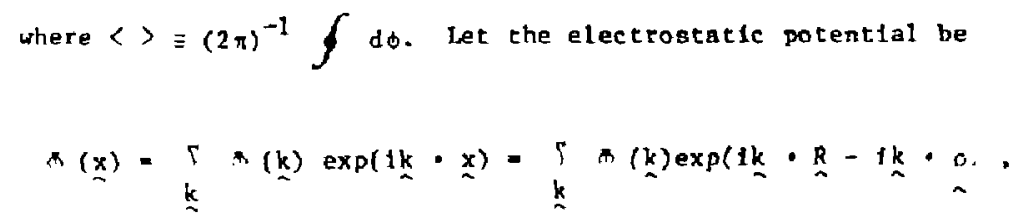

and lis gyrophase average hecomes

$$
\langle\sigma\rangle \equiv\langle\pi\rangle_{0}=\Gamma_{k} \Phi(k) J_{0}\left(\frac{k_{1} v_{1}}{\Gamma}\right) \exp (1 k \cdot n)
$$

In which

$$
\langle\exp ( \pm 1 k \cdot \rho)\rangle=J_{0}\left(k_{1} v_{1} / 0 !\right.
$$

is used, and $J_{0}$ is the Bessel function. From Eq. (9), the gyrophase-averaged Hlstribution can be expresser as

$$
\langle F\rangle=f+\frac{q}{m} \frac{\langle\infty}{B}=\frac{\lambda}{h} \frac{F}{L} .
$$

IIs ing the relatton

$$
\left\langle\exp \left[ \pm 1\left(k^{\prime}+k^{\prime \prime}\right) \cdot g \quad l\right\rangle=\sum_{n=\infty}^{\infty} J_{n}\left(\frac{k^{\prime} v}{\frac{1}{n}}\right) I_{n}\left(\frac{k^{\prime \prime} v 1}{0}\right) \cos \pi A,\right.
$$

where $\theta=\cos ^{-1}\left(k_{1}^{\prime} \cdot k_{\perp}^{\prime \prime} / k_{1}^{\prime} k_{1}^{\prime \prime}\right)$, the coupling term becomes

$$
\langle\omega \phi\rangle\langle\omega\rangle_{0}\langle\omega\rangle_{0}+2 \frac{\partial\langle\phi\rangle_{1}}{\partial R_{1}} \cdot \frac{\partial\langle\sigma\rangle_{1}}{\partial R_{1}},
$$

where only the first two leading term in Fq. (16) are kept and 
$\langle 0\rangle_{1}=\sum_{k} \Leftrightarrow(k) \frac{k_{1}}{k_{1}} J_{1}\left(\frac{k_{1} v_{1}}{\Omega}\right) \exp (t k \cdot n)$.

Wh the use of Eqs. (14) - (18), Eq. (12) reduces to

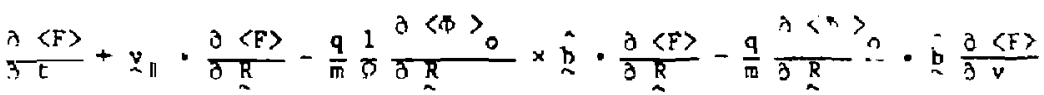

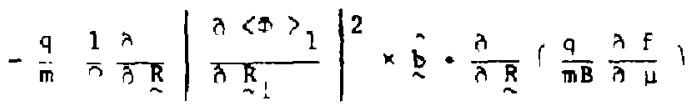

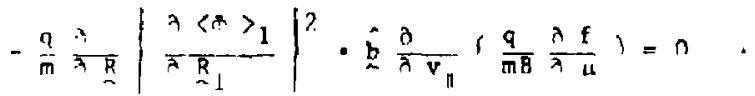

Assuming $f$ is Maxwellian in $v_{1}$, we found from $\mathrm{Fq}$. (19)

$$
F=\{F\}
$$

that

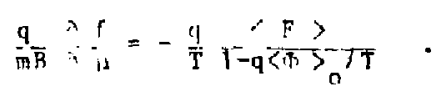

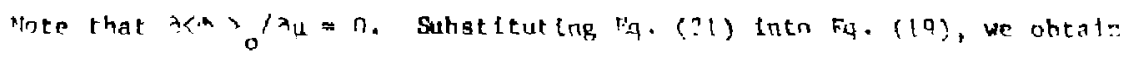

$$
\begin{aligned}
& \frac{\lambda\langle F\rangle}{7 t}+y_{\|} \cdot \frac{\lambda\langle F\rangle}{\partial \underset{\sim}{R}}-\frac{q}{m} \frac{l}{n}\left(\frac{\lambda}{\partial R} \sigma\langle A\rangle_{0}\right) \times \hat{b} \frac{\eta}{\lambda} \frac{\langle F\rangle}{R} \\
& \left.-\frac{q}{\mathrm{in}} r \frac{\lambda}{\hat{R}} a\langle\hbar\rangle_{0}\right) \cdot \hat{b} \frac{\partial\langle F\rangle}{\partial v_{\|}}
\end{aligned}
$$




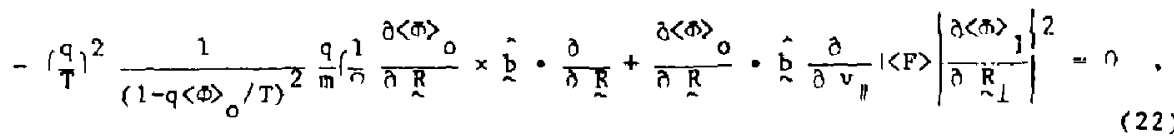

where

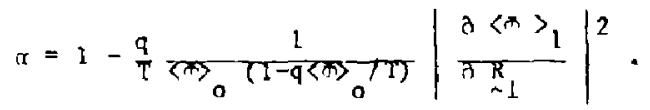

This equation, which is totaliy independent of to, describes the evolution of the guiding center distribution $\langle F\rangle$ in terms of the gyrophase-averaged field quantities. The original fistribution function $F$ in $\mathrm{Fq} .(9)$ is related to $\langle F\rangle$ through Eqs. (15) and (21) as

$$
F=\langle F\rangle-\frac{\langle F\rangle}{1-q\langle\Phi\rangle} T_{0} T T \frac{q}{T}\left(\Phi-\langle\pi\rangle_{0}\right)
$$

The next step is to transform the fteld quantittes from tige gutding center coordinates $\underset{\sim}{R}$ back to the particle coordinates $\underset{x}{x}$. This transformation can he accomplished by performing the integration of $f \therefore r^{\infty} v_{1}$ av 1 on Eq:. (2?) and (23) and assuming

$$
\langle F\rangle=F\left(\underset{\sim}{R}, v_{\|}, t\right) f_{m}\left(v_{1}\right),
$$

where $f_{m}$ is Maxpellian in $v_{1}$ and homogeneous spatially. The multiple-scale particle simulation mode1, ${ }^{14}$ witch is the extengion of the present scheme, has to be used to handle cases Involving the perpendleular temperature gradtent, L.e., $f_{m}=f_{m}\left(R, v_{1}\right)$. It is stralght forward to carry out the integration for

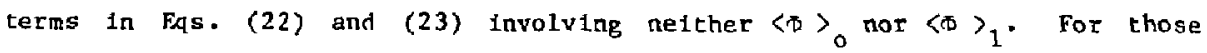
with $\langle\bar{T}\rangle_{0}$ only, the integration yfelds 


$$
\hat{\phi}(\underline{x})=\sum_{k} \quad(\underset{x}{k}) \Gamma_{0}\left(k_{1}^{2} v^{2} / 0^{2}\right) \exp (1 k \cdot \underset{\sim}{x}),
$$

where $v_{t}=(T / \pi)^{1 / 2}$ is the thermal veloctty, and

$$
r_{0}(b)=I_{0}(h) e^{-h}=\frac{1}{v_{t}^{2}} \int_{0}^{\infty} \exp \left(-v_{1}^{2} / 2 v_{t}^{2}\right) J_{0}^{2}\left(\frac{k_{1} v_{1}}{n}\right) v_{1} d v_{1},
$$

where $b=k_{\perp}^{2} \rho_{t}^{2}=k_{\perp}^{2} v^{2} / 0^{2}, I_{0}$ is the Bessel function. The tntegraturt of $\langle\omega\rangle_{0}\langle\Phi\rangle_{0}$ and $\langle\omega\rangle_{1}\langle\omega\rangle_{1}$ can be carried out usting Eq. (16), in which agaln on?y the two leading cerms are kept, and the Integrals of

$$
\begin{aligned}
& \frac{1}{v_{t}^{2}} \int_{0}^{\infty} \exp \left(-\frac{v_{1}^{2}}{2 v_{t}^{2}}\right) J_{0}^{2}\left(\frac{k_{1}^{*} v_{j}}{\sigma}\right) J_{0}^{2}\left(\frac{k_{\perp}^{*} v_{\perp}}{\rho}\right) v_{\perp} d v_{\perp} \\
& =\sum_{n=0}^{\infty} \frac{\left(n^{\prime}\right)^{n}}{n !} \frac{\partial^{n} \Gamma_{0}\left(b^{\prime}\right)}{\partial\left(b^{\prime}\right)^{n}} \frac{\left(b^{\prime \prime}\right)^{n}}{n !} \frac{\partial^{n} \Gamma_{0}\left(b^{\prime \prime}\right)}{\partial\left(b^{\prime \prime}\right)^{n}}=\Gamma_{0}\left(b^{\prime}\right) \Gamma_{0}\left(b^{\prime \prime}\right)+b^{\prime \prime}+\cdots, \\
& \frac{1}{v_{t}^{2}} \int_{0}^{\infty} \exp \left(-\frac{v_{1}^{2}}{2 v_{t}^{2}}\right) J_{0}\left(\frac{k_{1}^{v} v_{1}}{O}\right) J_{1}\left(\frac{k_{1}^{\prime} v_{1}}{O}\right) J_{0}\left(\frac{k_{1}^{*} v_{1}}{0}\right) J_{1}\left(\frac{k_{1}^{\prime \prime} v_{1}}{0}\right) v_{1} d v_{\perp} \\
& =\frac{1}{2}\left(b^{\prime}\right)^{1 / 2}\left(b^{\prime}\right)^{1 / 2}-\frac{3}{4}\left(b^{\prime}\right)^{1 / 2}\left(b^{\prime}\right)^{3 / 2}-\frac{3}{4}\left(b^{+}\right)^{7 / 2}\left(b^{\prime \prime}\right)^{1 / 2}+\ldots \text {, }
\end{aligned}
$$

.nd

$$
\frac{1}{v_{t}^{2}} \prod_{0}^{\infty} \exp \left(-v_{1}^{2} / 2 v_{t}^{2}\right) J_{1}^{2}\left(\frac{k_{1}^{\prime} v_{1}}{\bigcap}\right) J_{1}^{2}\left(\frac{k_{1}^{\prime \prime} v_{1}}{\varrho}\right) v_{1} d v_{i}=\frac{1}{2} b^{\prime} b^{\prime \prime}+\ldots
$$

where $b^{\prime}=k_{\perp}^{\prime 2} p_{t}^{2}$ and $b^{\prime \prime}=k_{\perp}^{\prime 2} p_{t}^{2}$. Congequently, the integration of $F \cdot$. (22) In $\phi$ and $v_{1}$ gives 


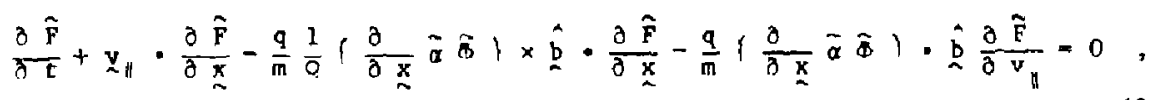

where

$$
\bar{\alpha}=1-\frac{q}{T} \frac{\rho_{t}^{2}}{?}\left|\frac{\partial \pi}{\lambda \underset{\wedge}{x}}\right|^{2} / \tilde{\Phi}
$$

and the integration of Eq. (23) In and $v$, as well as tn $v_{n}$ yields

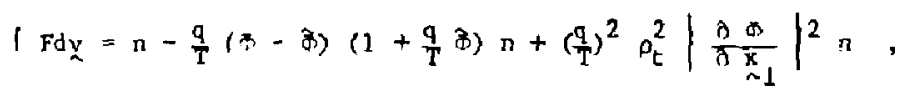

where

$$
n=\int_{-\infty}^{\infty} \hat{\mathrm{F}}\left(x_{i}^{x}, v_{y}, t\right) d v_{i} .
$$

Since the difference between the particle coordinates $;$ and the guiding-center coordinates $\mathrm{R}$ vanishes after two gyrophase-averaging processes, the independent vartables in Eq. (30) are now $x, v_{i l}$, t. The potentials * $(x)$ and $\bar{x}(x)$ are deftsed by Eqs. (13) and (25), respectively. It should he pointer out here that the terms of the orders of $\left\langle k_{1}^{2} \rho_{t}^{2}{ }^{2}(q \delta / T)^{2}\right.$ and $\left(k_{\perp}^{2} \rho_{t}^{2}\right)\left(q_{q}=/ T\right)^{3}$ have heen neglected in obtaintog Eqs. (30) and (31). Thus, the term $\%$ in $\mathrm{Fq}$. (31) is accurate only to $\mathrm{k}_{1}^{2} \mathrm{p}_{\mathrm{t}}^{2}$. From $\mathrm{F}_{\mathrm{q}} \mathrm{s} .(31)$ and (32), Potsson's equation can then be wrttern as

$$
\nabla^{2} \sigma-k_{D 1}^{2} \frac{n_{1}}{n_{0}}\left[(\Phi-\delta)-\frac{p_{1}^{2}}{2} \nabla_{1}^{2} \frac{e \Phi^{2}}{T_{1}}\right]=-4 \pi e\left(n_{1}-n_{e}\right)
$$

where subscriprs 1 and $e$ denote spectes, $k_{01}^{2}=4 \pi e^{2} n_{0} / T_{1}$ and $n_{0}$ is the spatial 
average of $n_{1}$. Here electron gyrorac' us effects are asgumed to he amili and nep lected.

tt is luteresting to observe that the gyrokinetfc equition, 8 . (30), in essence is a drtft-ktnetic quation with a gyrophase-guerared fielf $\hat{x}$, and the second term on the left-hand side of Eq. (33) accounts for the i latization effects. Furthermi:e, F, which is related ro the phasemigeraped quantity $\langle F\rangle$ in Eq. (24), is now the guiding-center distrihution and $n$ is the gulding-center density. Thus, the actual number density assoctated wlth the orlginal fistribution $F$ consists of two parts, $1 . e$, the puldin, -center number Henstly and the density due to polarlzation effects, as shown in Fq. ( 31$)$. Fquatlons ( $3 n),(3 ?)$ and (3?) form a convenlent set of equat lons that can he used for the particle pusting. Mareover, since these equations are simply the usial gyrokinet1c-Polsson system casting in a differenc form, they can also he used for analytical purposes. Contrary to the usual gyroktnetic formulation, the present scheme retatns the gyroradius effects without the subsidiary ordering of the distrlhutton function F. These fiquations are correct 1 tnearly for arbltrary vajues of $k_{1} \rho_{t}$ and nonlinearly for $k_{1} p_{t}<1$. The incluston of the gyroradius effects to the next order, $1 . e .,\left(k_{L}^{2} \rho_{t}^{2}\right)^{2}(7 \Phi / T)^{2}$, can easily be accomplished by retalning the corresponting termg in Fus. i27) - (29) in the derlvation. Since the resulting formulation 19 somethat tedlous, we prefer not to Alscuss it at the pregent time. The extenston of the present schene to Inclute termg of the orter of $\left(k_{1}^{2} \rho_{1}^{2}\right)(q \pi / T)^{3}$ and beyond requtres the rechnique tesctilieit in Ref. 14.

The definteion of actual number density, Fq. (7l), In the ahsence of the perturhed fleits neeris furcher dtscusglon. tet's define

$$
\hat{\pi}(\underline{x})=\int F d \underline{r}
$$


and

$$
\left.\hat{n}(k)=\frac{1}{L}\right\} ! F \exp (-1 \underline{k} \cdot \underline{x}) d \underline{x} d \underline{\sim} .
$$

Since Jacohian, $J(x, v / R, y)$, is unity in the slah geometry, the latter can he wrttten as

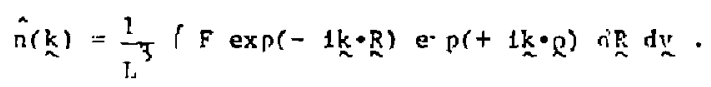

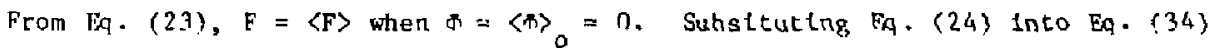
and carrylng out the Integracion In $\underset{\sim}{\mathrm{p}}$, we obtain

$$
\hat{n}(k)=\frac{l}{L^{3}} \int \pi \exp \left(-\frac{k^{2} p_{t}^{2}}{2}\right) \exp (-1 k \cdot R) d \underline{\sim},
$$

where

$$
\frac{1}{v_{t}^{2}} \int_{0}^{\infty} \exp \left(-\frac{v_{1}^{2}}{2 v_{t}^{2}}\right) J_{0}\left(\frac{k_{1}^{v}{ }^{v}}{\rho} v_{1} d v_{1}=\exp \left(-\frac{k_{1}^{2} p_{t}^{2}}{2}\right)\right.
$$

has been used, and $\mathrm{n}(\underset{\sim}{\mathrm{R}})=\int \mathrm{F} d v_{\|}$ls gutding center number density. For $k_{1}^{2} p_{t}<<1$ where $k_{1}$ describes the equilthrium vartation, Eq. (35) gives

$$
\hat{n}(x)=n+\frac{1}{2} \rho_{\tau}^{2} \nabla_{1}^{2} n
$$

Hence, the actual number density asscilated with the distribution function $F$ should include the contribution from equilibrium denstey gradient. fFor zases with a temperature gradient, $1 . e .$, for $t_{\operatorname{mo}}\left(R_{2}, v_{L}\right)$, the contribution is (1/2) $\nabla_{1}^{2} \rho_{t}^{2} a_{1}$ Accordingly, the 1on guiding center number density $n_{1}$ on the 
right-hand afde of Polsson's equation, Eq. (33), should be replaced by $\hat{n}_{1}(x)$ in Eg. (36), and becomes

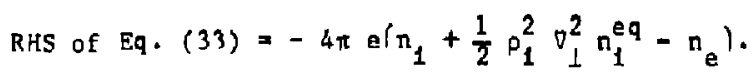

Here $\mathrm{n}_{1}^{\text {eq }}$ represent the part of the fon gulding center number density when the perturhed fielts are absent, whereas $n_{t}$ is the total number densfey. The contrihution of this additional tem is usually very small ant has been neplecter in most analycical srudies. However, for some cases in the particle simulation, 1ts presence crnnot be ignored because of the large density gratient used and the boundary conditions Imposed for Polsson's equation.

\section{Ryraidine:1c Simulation Code and Results}

As we tave mentioned earlier, the regulting gyrokinetic equation, Eq. (3n), resembles closely the usual drift-kinetic equation. Using the distrihution function Fे in its diserete form,

$$
\hat{E}\left(\underset{n}{x}, v_{\eta}, t\right)=\sum_{1=1}^{N} 5\left\{x_{-1}^{x}-x_{1}(t)\right] \delta\left[v_{\|}-v_{\| 1}(t)\right],
$$

where $N$ is the total number of particles of the pirtcular gpecies in the system, we obtain from Fq. (3n) the equations of motion for the 1-th particle:

$$
\frac{d x_{1}}{\pi E}=\underline{y}_{\| 1}-\left.\frac{q}{m} \frac{1}{\delta} \frac{\partial(\tilde{a})}{\partial x_{n}}\right|_{x_{1}}, t \times \hat{b}
$$

$$
\frac{d v_{11}}{d t}=-\left.\frac{q}{n} \frac{\partial(\tilde{\alpha} \tilde{\sigma})}{\partial \underline{x}}\right|_{x_{1}, t} \cdot \hat{b}
$$


which are simply the charactertatica of $\mathrm{Eq}$. (30). They are the basle equations for our particle purhing and can be solved numerically using the usual predictor-corrector fance-difference scheme. 6 In the code, the lons are pushed with a modified potential of $\widetilde{\alpha}$, delined $t r$ Eqs. (25) and (36), while the electrons are acted upan by the orfginal potential $\$$. Since the particle gyration has been eliminated from the equations of motfon, longer time-steps corresponding to the frequency of intsrest may be used in Fas. (39). The additionai constratnt of $k v_{t} \wedge t<1$ ordinarlly does not pose any proilen for our nurposes. At every time step tho number denstey is calcriated hy

$$
n=\sum_{n=1}^{N} \delta\left[x-x_{\sim !}(t)\right]
$$

and is substituted Into Polsson's equation, Eqs. (33) and (37), to determine $\Phi$. The modifled Polssan's equation without the $\pi^{2}$ term is in the form of an linhoriogeneous Fredholm equation of the second kind in the Foulfer k-space, and $t$ can be solved readily using the method of successtve approximatous, 15 with the constraint that number dens'.'y assoctated with the polarlzation effects is conserved. The small nonlinear term can he Includet perturbatively. The datermination of $n_{1}^{e q}$ in $5 \mathcal{A}$. (37) is somewhat difficult due to particle diffusion turing the course of the simulation. However, it can $\mathrm{ke}$ approximated hy taking the mean of the spatial averages of elect on and fon number densitfes in the homogeneous directions, $1 . e .$,

$$
n_{1}^{e q}=\left\langle n_{1}+n_{e}\right\rangle_{\text {homo. }} / 2 \text {. }
$$

This ambigutey can be removed in the multiple gcale particle simulation 
model. 14

The gyrokinetic particle simulation ochene has been implementer in a twoand-one-hal $\dot{t}$ dimensional $\left(x, y, v_{x}, v_{y}, v_{z}\right)$ code $t n$ the slah peometry. To simplify its algorithin we have dropped all of the nonlineat as

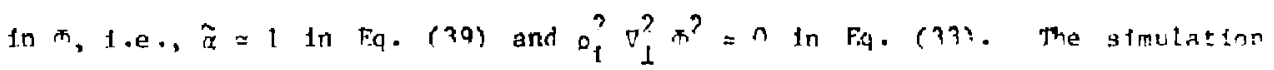
plasma is bounded by two conducting walls in the $x$ Atrection where the potential wantshes and the simple reflecting conditlon is imposed for the particles hitting the wall. The perfodic conditian is uset for hoth the waves and the particles in the $y$ direction. The magnetic field is in the $y-r$ plane where $B_{z}>B_{y}$. In the case of shear, $B_{y}$ is a function of $x$. The inhomogenefty extsts only in the $x$ directon with a constant $k(J-n / n)$. To cases, one with shear and the other without, have been studted usting the code. The results agree very well in every aspect of the Instability with those obtalned from the core whlch uses exart dynamlcs for the luns and

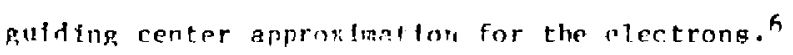

Case 1

Thls is a shparless case. Istng the prid qize $\wedge$ as a hadi lutt, the atmulation paranetera are

$$
\begin{aligned}
& \mathrm{L}_{\mathrm{x}} \times \mathrm{I}_{\mathrm{y}}=64 \Lambda \times 12 \Lambda, \mathrm{n}_{0}=36 / \Lambda^{?}, \mathrm{In}_{\mathrm{l}} / \mathrm{m}_{\mathrm{p}}=18.77 \\
& T_{e} / T_{1}=9, \omega_{c e} / \omega_{p e}=1 n, \lambda_{n e} / \Lambda=1.5 \text {, partlcle stze/A }=1.5 \text {, } \\
& B_{y} / B_{z}=0.0 n 59, o_{f} / A=? .14, k p_{1}=0.15, \\
& k_{y} p_{1}=0.42 R_{m}, w^{*} / \omega_{p e}=0.00315 m \text {, where } m=0, \pm 1, \pm 2, \cdots
\end{aligned}
$$


The simulation has been cartled out with $\omega_{p e} \Delta t=80$ using the gyrokinetic code. The time evolution of $0 / T_{e}$ for the most unstable $m=1$ mode measured at the midile of the plagma in $x$ and the corresponding frequency spectra are shown in Fig. 1.16 simulation results from the prevtous corle with $\omega_{p e} \Delta t=25$ are shown in Fig. 2 . The apreement hetween the two is excellent in terms of the Ineat frequency and growth rate, the saturation amplitude and the nonithear frequency shift. The higher saturation ampliture in the gyrokinetlc code 1 probahly caused by the absence of nonltnear $\delta^{2}$ terms. As we can see, the stmulation plasma is much quieter in the gyrokinetic code hecause of the elimination of the ian gyromotion. Thus, we can afford to use fewet particles and milder density gradlent in the simulation. It should also be mentoned here that the ohserved linear propertles of the instability agree with the theory.12 The nanltnear saturation and the frequency shift are mainly the result of the mode coupling processes. 17 The effect of $n_{1}^{e q}$ in Fq. (37) on the Instabtlity is instgnificant tn this case.

Case?

In thts case, shear is incluted and the magnetlc field is descrthed hy

$B=B_{0}\left(\hat{z}+\hat{\chi} \times / L_{s}\right)$,

where $L_{s}$ is the shear scale length. The rational surface $x=0$ is locaced at the left-hand boundary of the system. Therefore, we only allow odd modes in the strulation. The other parameters are

$$
L_{x} \times L_{y}=64 \Delta \times 32 \Delta, n_{0}=1.6 / \Delta^{2}, m_{1} / m_{e}=100
$$




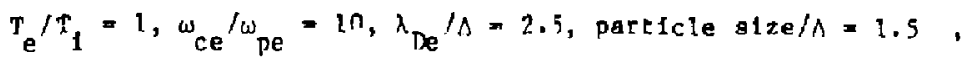

$$
\begin{aligned}
& \rho_{1} / \Delta=2.5, \alpha_{1}=0_{1} / L_{n}=0.175, L_{g} / L_{n}=56, \\
& k_{y} p_{1}=0.310, \omega^{*} / \omega_{p e}=r .00875 \mathrm{~m} \text {, where } \mathrm{m}=0, \pm 1, \pm 2, \ldots
\end{aligned}
$$

The time strp in the gyrokinetic code is $\omega_{p e} \Delta t=4 n$, and the tarm assoctated with neq in Eq. (5T) is also included. Figure 3 shows tha regults for the most unstable $m=1$ morle where the tine evolution of $\mathrm{e} / \mathrm{T}$ at $\mathrm{x} / \mathrm{A}=25$ and the moive structure for $\left(\mathrm{a} / u^{*}=\Pi, 7\right.$ are given. The corresponding results fr.m the prevlous code with $\omega_{p e} \Delta t=4$ are shown In Fig. 4. In hoth cases a band-pass Filter wh the with of w* has heen applied to eliminate the numertcal natse In em/ $\mathrm{e}_{\mathrm{e}}$. The mode structures are ohtalned throuph the use of the two-pointspatlat correlation function. 13 tgatn, the two results are very sintlar. The nature of the instahility, which 18 not a bona fide elge:morle, has heen Aiscusser in Ref.13. When the term involving neq is not Included in the ryrokinetic simulation, somewhat different results have heen ohtalned. In this case, the frequency $1 \mathrm{~s}$ lower, $(1) / \omega^{\star}=0.5$, and the saturatlot ampit 1 tude $1 \mathrm{~s}$ also lower, $e^{m / T_{e}}=4 \%$ Apparently, the amblpolar potenta' arising from ieq has played a part tn the instabllity.

From the two cases studied here, one can conclude that the gyroklaetic code can Indeed reproduce all the relevant physlcs in drift fistabllicles whth considerable saving in computing resources. The time-steps used in these two corles show a galn of a factor of $5 \sim 10$. Compared with the conventlonal codeg where exact dyamicg is preserved for hoth electrons and long and the timestep $1 \mathrm{~s} 1 \mathrm{im}$ ted hy $\omega_{\text {pe }} \leq n .2$, the gain can he as high as 2 - 7 orters of magniturle. Moreover, the simuletion plasma 19 much quieter which makes the Interpretation and the understanding of the resul.ts much easier. 


\section{Conclustons}

We have presented in this paper a new scheme for particle simulation haser on the gyrokinettc approach. A 2-1/2-rimengional electrostatic code in the slab geometry utflizing the scheme has given satisfactory results. There are numerous advantages in using this code for studying microinstabilities long ilme-gtep being one of them. In conjunction with the multiple-scale morlel, 14 the code can be user to study the phenomena assoctated with steady state drift turbulence such as anomalous jarticle and energy diffusion. Its extension to a fully 3. IImensional code similar to those In Ref. 7 should be stralghtforwart. The procedures given In sec. III also serve as a gutre fir the development of comparable schemes for simulating electrostalic and low-B plasmas in the toroldal geometry. The assumption, that the distrihution function is Maxbellian in $v_{1}$ leading to Fqs. (30) and (33), can prohatly the removed by performing the second gyrophase-averaging numerically. Such a scheme has yet to be devised. Better stlli, tf ane could obtain an efftctent particle simulation scheme based on Eqs. (11) or (12) alone without the prlor gyrophase-averaging processes, arbicrary values of $k_{1} \rho_{1}$ could then be preserved in the nonitnear dymamics. 


\section{Acknowledgments}

The author wishes to thank Dr. W. M. Tang, Dr. L. Chen, and Or. F. W. Perkins for thelr continuing interest in this work and tinelr helpful comments. Mscussions with Dr. C. Oberman and Dr. P. Catto ate ilss prateful ly acknowlenged.

This work is supporter by the U.s. Depertment of Energy Contract No. DF.ACก2-CHO-3ก7\%. 


\section{References}

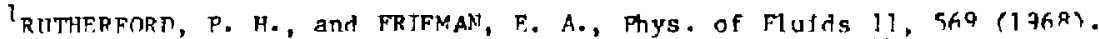

'TAYLOR, J. B., and HASTJF, P. i., Plasma Phys. 10,470 (106\%).

${ }^{3}$ ratTh, P. J., Plasma Phys. 20,710 (197a).

${ }^{4}$ CHFNG, C. 7. , and OKIIDA, H., Phys. Rev. tett. $39,7 n g(1977)$.

5.E.E, W. W., CHANCF, M. 5, and OKUDA, M., Phys. Rev. lett. 46, $1675(1981)$.

fLFE, W. W., and UKUMA, H., J. Comput. Phys. 26, $139(1979)$.

T.iENS, C. Z., and OKIMA, H., J. Comput Phys. 25, 133 (1977).

Ri.F., W. W., OKLINA, H., and NEVINS, W. M. (In preparation).

nA.SON, R. t. (to apear in at. Comput. Phys.).

InTFNAIT, J. (to appear in J. Comput. Phys.).

11 FRIFMMAN, A., LANGMON, A. R., and COHEN, R. T., ICGRI-86POL, Lawrence Tivermore National Tahoratory, Tivermore, C.A (19R1).

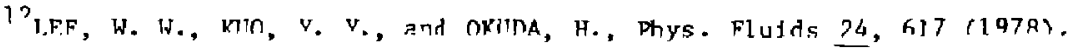

13 I.EF, W. H., NFVINS, W. M., OVIMA, H.: and WHITF, R. R., Phys. Rev. T.ett. $43,347(1979)$.

14 T.FF, H. W., and CHEN, I. (to preparalton?.

15 See for example, T. Stakgold, Boundary Value Problems of Mathemattcal Phystes (MacM11lan, New York, 1967), Vol. 1.

16 The dtagnostic package ZFD by $W$. M. Nevins has heen used to ortaln the data given here.

${ }^{17}$ LEE, W. W., TANS, W. M., CHENS, C. 2. and CHEN, I., Bull An. Physe. Soc. 26, 1012 (1091). 


\section{Figure Captions}

E1g. 1. The evaluation of es/ $T_{e}$ for the $m=1$ mode and the corrsponding frequency spectrum (measured at the middle of the system it: $x$ ) wing the gyrokinetlc code.

Fig. 3. Time evolution of es/T for $m=1$ mode and tie corresponding frequency spectrum (measured at the mindle of the system in ir) ustag the previous core.

Fig. 3. Thme evolution of ew/ $T_{e}$ for the $m=1$ mode at $x / s=r 5$ and the corresponting mode structure for $\omega / \omega^{*}=0.7$ using the gyrokinertc code.

Fig. 4. Time evolution of $e \bar{\phi} / T_{e}$ for $m=1$ mode at $x / \Delta=25$ and the corresponding mode structure for $\omega / w^{\star}=0.7$ using the prevtous code. 
\# 81 10258
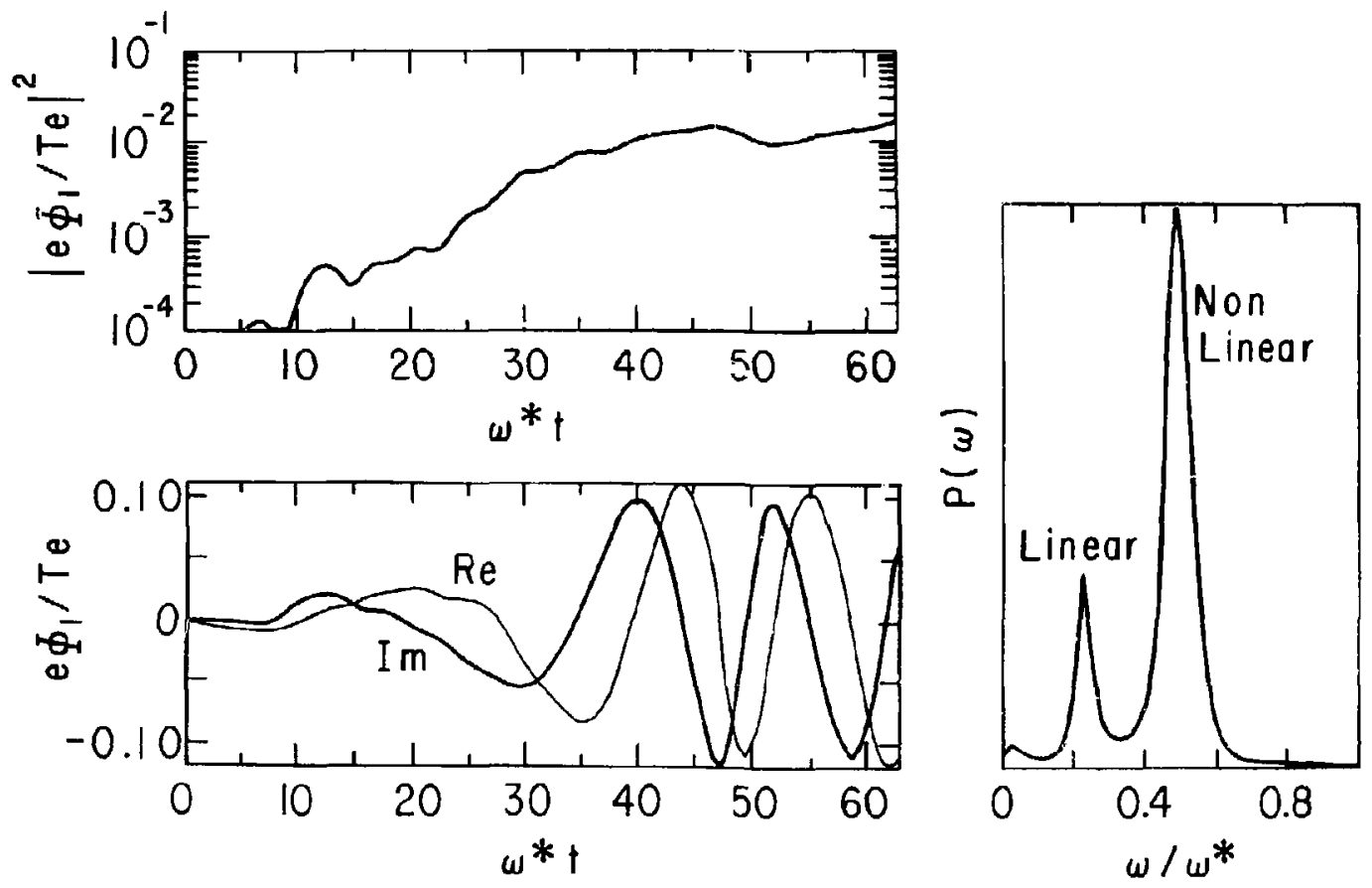
\# 81T0259
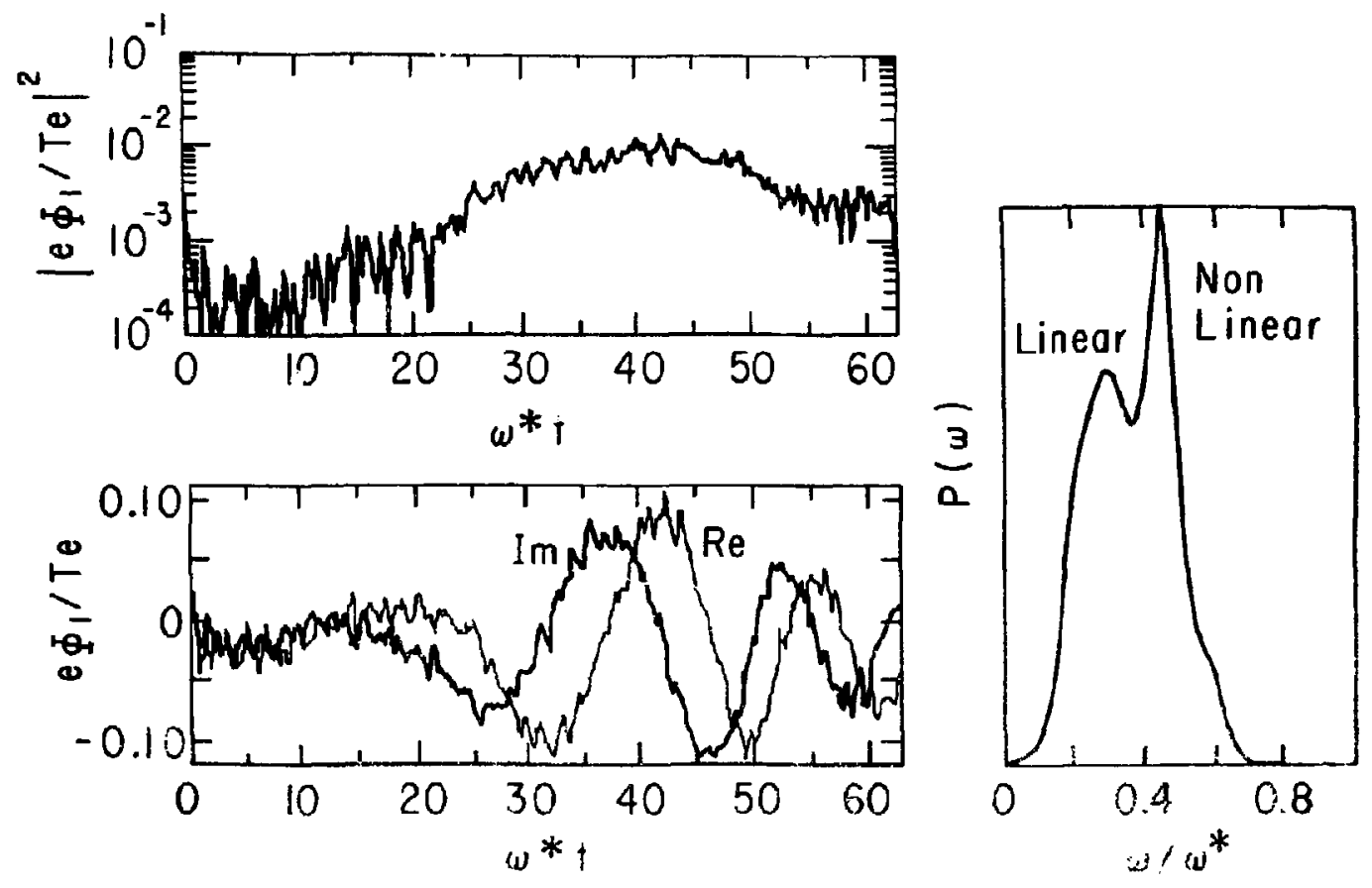
\# 81T0256
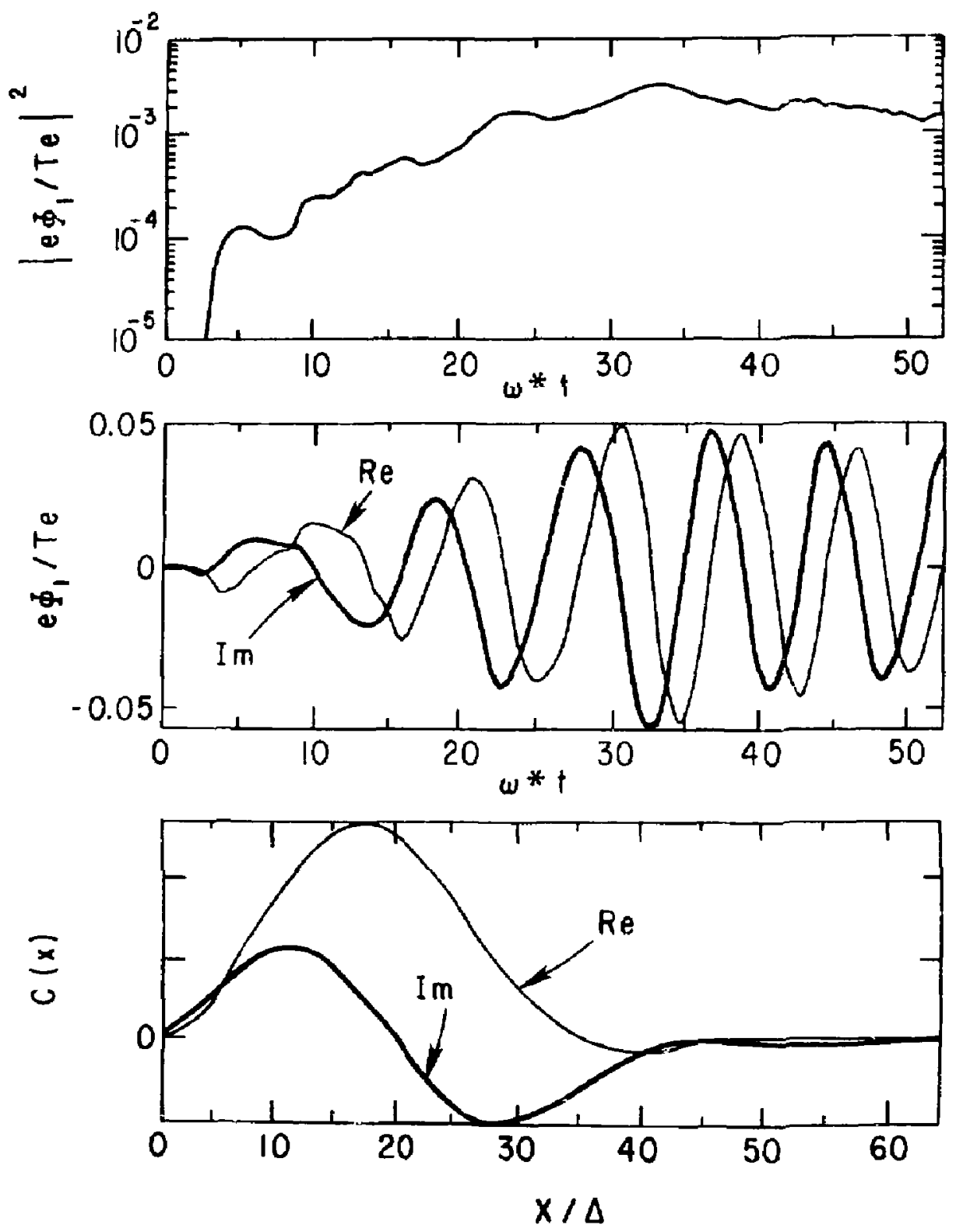

Fig. 3 

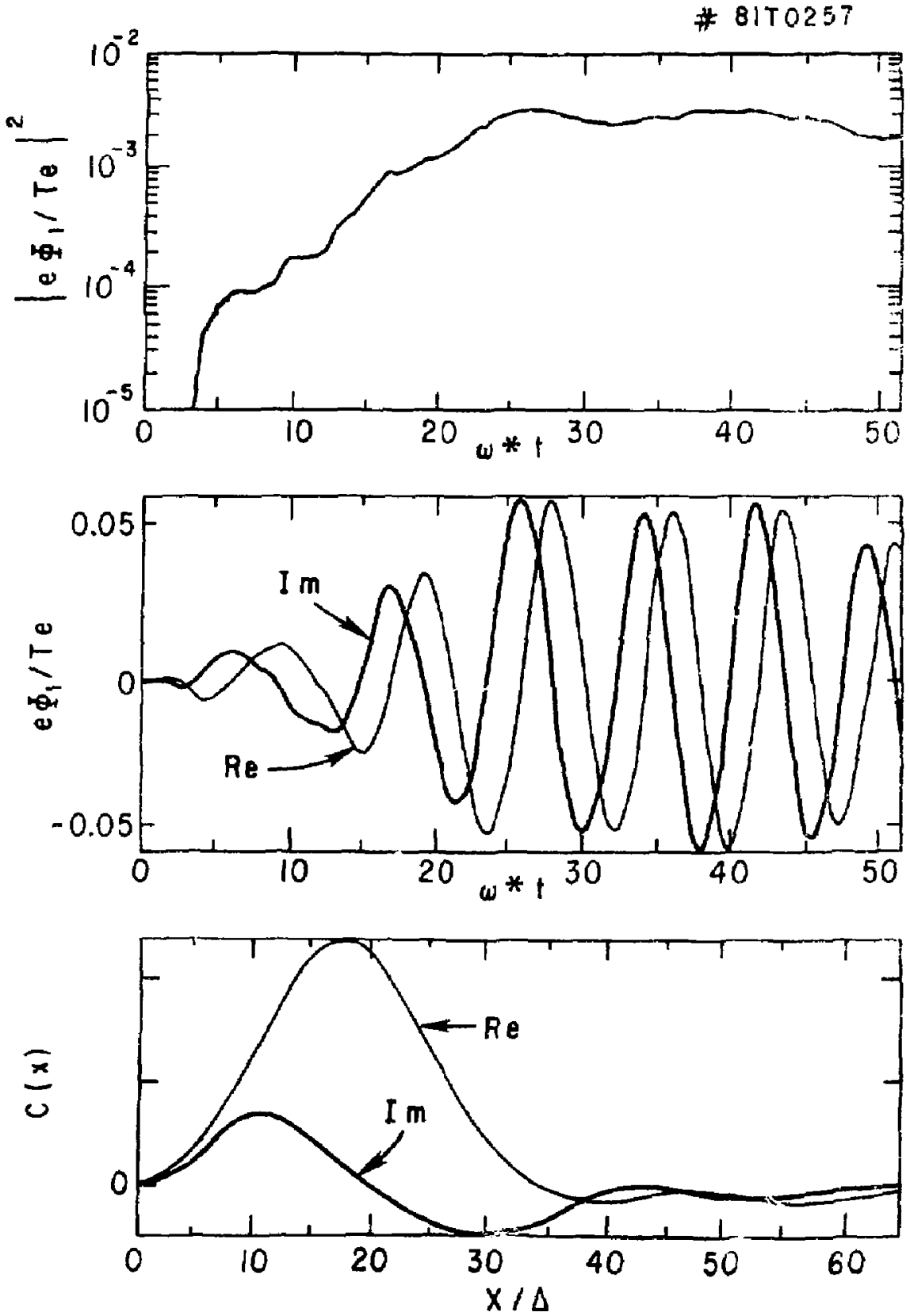

Fig, 4 